\title{
Flora dan fauna pada ekosistem lahan gambut dan status perlindungannya dalam hukum nasional dan internasional
}

\author{
A. Pramudianto ${ }^{1 *}$ \\ ${ }^{1}$ Sekolah Ilmu Lingkungan, Universitas Indonesia, Jakarta, Indonesia
}

\begin{abstract}
Abstrak.
Ekosistem gambut sangat berperan dalam kehidupan bumi dan memiliki beberapa fungsi penting seperti ekologis, ekonomi dan sebagainya. Keanekaragaman hayati (flora dan fauna) ekosistem gambut cukup tinggi. Beberapa jenis flora seperti ramin dan jelutung rawa, serta jenis fauna seperti buaya, orang utan dan ikan ditemukan di ekosistem gambut. Status perlindungan terhadap flora dan fauna diatur dalam perangkat hukum nasional (Undang-undang dan Peraturan pelaksanaan). Perangkat hukum internasional yang bersifat hard law seperti Convention on International on Trade in Endangered Species for Wildlife Flora and Fauna (CITES) tahun 1973 mengatur flora dan fauna yang diperdagangkan. Perangkat non hukum seperti International Union Conservation for Nature (IUCN) Red Data List mengatur status flora dan fauna. Artikel ini menggambarkan status flora dan fauna pada ekosistem gambut serta upaya perlindungannya. Penelitian ini menggunakan metode yuridis normatif dengan pendekatan deskriptif analisis. Hasilnya menunjukkan bahwa pohon ramin dan buaya diatur dalam CITES 1973. Beberapa jenis flora dan fauna lainnya termasuk dalam IUCN Red Data List dengan berbagai status seperti terancam, langka, dan sebagainya. Harapan dari penelitian ini adalah dapat menggambarkan keberadaan flora dan fauna di ekosistem lahan gambut terutama dari aspek hukum nasional dan internasional.
\end{abstract}

Kata kunci: ekosistem gambut, CITES, IUCN red data list

\begin{abstract}
.
Peat ecosystems play an important role in the life of the earth and have several important functions such as ecology, economics and so on. The biodiversity (flora and fauna) of the peat ecosystem is quite high. Some flora such as ramin, jelutung swamp, and fauna such as crocodiles, orangutans, and fish are quite diverse found in the peat ecosystem. The status of protection of flora and fauna is regulated in national legal instruments such as laws and other implementing regulations. The instruments of international law (hard law) such as the Convention on International on Trade in Endangered Species for Wildlife Flora and Fauna (CITES 1973) regulates flora and fauna especially those traded. Non-legal devices such as the International Union for Conservation of Nature (IUCN) Red Data List regulates the status of flora and fauna. This article describes the status of flora and fauna in the peat ecosystem and its safeguards. This study used a normative juridical method with a descriptive analysis approach. The results showed that ramin tree and crocodile are arranged in CITES 1973. Several other types of flora and fauna are included in the IUCN Red Data List with various statuses such as threatened, rare, and so on. The hope of this study was to be able to describe the presence of flora and fauna in peatland ecosystems especially from national and international legal aspects.
\end{abstract}

Keywords: peat ecosystem, CITES, IUCN red data list

\section{PENDAHULUAN}

Ekosistem lahan gambut telah menjadi perhatian penting dalam beberapa tahun terakhir ini karena semakin menyusut. Layaknya ekosistem lahan basah yang memiliki berbagai fungsi, ekosistem lahan gambut juga memiliki berbagai fungsi diantaranya sebagai pengatur sistem hidrologi, perlindungan keanekaragaman hayati, sumber energi, lahan budi daya, penyerap karbon dan menjaga kestabilan iklim, dll.

Menurut Suryadiputra et al. (2005), ekosistem lahan gambut tropis yang ada di seluruh dunia meliputi areal seluas 40 juta hektar dan 50\% (20 juta hektar) diantaranya terdapat di Indonesia (Sumatera, Kalimantan, Papua dan sedikit Sulawesi). Ekosistem lahan gambut, merupakan salah satu ekosistem

\footnotetext{
${ }^{*}$ Korespondensi Penulis

Email : andreas.pramudianto@gmail.com
} 
lahan basah yang memiliki karakteristik yang unik. Lahan gambut yang basah ternyata cenderung mudah terbakar karena kandungan bahan organik yang tinggi dan memiliki sifat kering yang tak balik, porositas tinggi dan daya hantar hidrolik vertikal yang rendah (Najiyati et al. 2005a).

Berdasarkan PP Nomor 71 Tahun 2014 tentang Perlindungan dan Pengelolaan Ekosistem Gambut bagian penjelasannya menyatakan bahwa untuk mencegah perubahan fungsi gambut, setiap negara mempunyai kepentingan yang sama untuk mempertahankan dan meningkatkan fungsi gambut agar Gambut sebagai sumber daya alam dan fungsi penyeimbang iklim dapat dimanfaatkan sebesar-besarnya untuk kesejahteraan masyarakat, baik untuk generasi saat ini maupun mendatang, serta untuk masyarakat nasional maupun global.

Persoalan gambut termasuk sebagai ekosistem bukan hanya menjadi perhatian nasional, namun juga masyarakat internasional. Salah satu peran penting ekosistem lahan gambut adalah sebagai habitat berbagai flora dan fauna yang juga akan menentukan kondisi keanekaragaman hayati nasional maupun global. Selain flora dan fauna, dalam ekosistem lahan gambut juga terdapat plasma nutfah baik yang endemik maupun yang bukan endemik. Flora dan fauna serta plasma nutfah yang ada pada ekosistem lahan gambut harus diupayakan perlindungan dan pengelolaannya demi generasi masa depan.

Konsep perlindungan dan pengelolaan ekosistem lahan gambut dilakukan melalui perencanaan, pemanfaatan, pengendalian, pemeliharaan, serta sanksi administratif. Selain itu ekosistem lahan gambut ada yang termasuk lindung dan budi daya. Gambut yang termasuk lindung, ekosistem ini dapat saja berada di Taman Nasional, Hutan Lindung, Suaka Alam, Cagar Alam dan kawasan perlindungan lainnya. Sementara itu status ekosistem lahan gambut yang termasuk budi daya dapat saja berada dalam kawasan Hak Pengusahaan Hutan (HPH), budi daya tambak, pertanian, perikanan darat dan kawasan budi daya lainnya.

Ekosistem lahan gambut saat ini menjadi sangat penting, mengingat banyak persoalan bencana lingkungan seperti meluasnya kebakaran hutan, disebabkan keberadaan ekosistem ini kurang mendapat perlindungan yang baik. Misalnya kebakaran hutan yang awalnya pada hutan biasa kemudian meluas pada ekosistem lahan gambut, mengakibatkan sulit dan lama untuk dipadamkan. Ekosistem ini juga kaya akan flora dan fauna yang harus dilindungi. Komitmen internasional dan nasional pada perlindungan ekosistem lahan gambut yang juga sebagai habitat flora dan fauna seharusnya semakin kuat untuk dilakukan. Apalagi komitmen Indonesia terhadap Paris Agreement tahun 2015 dalam upaya mengatasi perubahan iklim melalui NDC (National Determind Contribution) juga 
harus memperhitungkan keberadaan ekosistem lahan gambut sebagai penyerap karbondioksida $\left(\mathrm{CO}_{2}\right)$.

\section{METODOLOGI}

Penelitian ini bersifat desk study, studi pustaka, studi regulasi nasional dan internasional yang mengatur tentang status dan kelangkaan flora dan fauna. Penelitian menggunakan metode yuridis normatif dengan pendekatan deskriptif analisis.

\section{HASIL DAN PEMBAHASAN}

\subsection{Pengertian dan karakteristik ekosistem lahan gambut}

Ekosistem lahan gambut merupakan salah satu ekosistem lahan basah. Ekosistem lahan basah dapat diketahui definisinya dari Ramsar Convention yang mendefinisikan sebagai berikut:

"Wetlands are definined as area of marsh, fen, peatland or water, whether natural or artificial, permanent or temporary, with water that is static or flowing, fresh, brackish or salt, including areas of marine water the depth of which at low tide does not exceed six metres".

Berkaitan dengan ekosistem lahan gambut, dikenal juga lahan rawa yang menurut PP Nomor 27 Tahun 1991 adalah genangan air secara alamiah yang terjadi terus menerus atau musiman akibat drainase alamiah yang terhambat dan mempunyai ciri-ciri khusus baik fisik, kimia maupun biologi. Diatur pula dalam PerMenPU Nomor 64/PRT/1993 bahwa lahan rawa dibedakan menjadi dua yakni rawa pasang surut/rawa pantai dan rawa non pasang surut/rawa pedalaman.

Definisi gambut menurut Driessen (1978) dalam Najiyati et al. (2005b) adalah tanah yang memiliki kandungan bahan organik lebih dari 65\% (berat kering) dan ketebalan gambut lebih dari 0,5 m. Soil Taxonomy dalam Najiyati et al. (2005b) mendefinisikan gambut adalah tanah yang tersusun dari bahan organik dengan ketebalan lebih dari $40 \mathrm{~cm}$ atau $60 \mathrm{~cm}$, tergantung dari berat jenis dan tingkat dekomposisi bahan organiknya.

Berdasarkan Pasal 1 angka 2 PP Nomor 57 Tahun 2016 tentang Perubahan Atas PP Nomor 71 Tahun 2014 tentang Perlindungan dan Pengelolaan Ekosistem Gambut, gambut adalah material organik yang terbentuk secara alami dari sisa-sisa tumbuhan yang terdekomposisi tidak sempurna dengan ketebalan $50 \mathrm{~cm}$ atau lebih dan terakumulasi pada rawa. Lahan gambut dapat membentuk ekosistem, sehingga pengertian ekosistem gambut berdasarkan PP tersebut adalah tatanan unsur gambut yang merupakan satu kesatuan utuh menyeluruh yang saling mempengaruhi dalam membentuk keseimbangan, stabilitas, dan produktivitasnya. 
Menurut PP Nomor 57 Tahun 2016 tentang Perubahan Atas PP Nomor 71 Tahun 2014 dinyatakan pula bahwa gambut mempunyai karakteristik yang unik, selain sebagai komponen lahan basah, komponen dari ruang daratan, juga komponen lingkungan hidup. Selain itu gambut memiliki fungsi yang beragam dalam perikehidupan bangsa Indonesia, antara lain sebagai sumber daya alam berupa plasma nutfah dan komoditi kayu, sebagai tempat hidup ikan, dan sebagai gudang penyimpan karbon sehingga berperan sebagai penyeimbang iklim.

\subsection{Berbagai jenis flora dan fauna pada ekosistem lahan gambut}

Mudiyarso et al. (2004) menyebutkan terdapat flora khususnya kayu yang terdapat dalam ekosistem lahan gambut seperti Gelam (Mellaleuca sp.), Ramin (Gonystylus bancanus), Meranti (Sharea spp.) dan Damar (Agathis dammara). Sementara itu menurut Mudiyarso et al. (2004) dalam penelitian pendugaan cadangan karbon, terdapat lebih dari 50 spesies pohon hutan gambut.

Menurut Iqbal dan Setijono (2011) di Hutan Rawa Gambut MerangKepayang terdapat 178 jenis pohon yang dilindungi diantaranya pulai rawa (Alstonia pneumatophore), jelutung rawa (Dyera costulata) dan Mengris (Kompassia malacensis). Sementara itu menurut Najiyati et al. (2005b) ada berbagai jenis tanaman untuk keperluan pertanian yang cocok ditanam di lahan gambut dengan membagi menjadi tanaman pangan, tanaman perkebunan, tanaman sayuran, tanaman buah-buahan, tanaman rempah dan minyak asri, tanaman serat dan tanaman lainnya. Tanaman pangan yang dapat ditanam diantaranya sagu (Metroxylem sagu), padi (Oryza sativa), sukun (Artocarpus communis) dan beberapa jenis lainnya. Tanaman lainnya seperti Meranti rawa (Shorea pauciflora), Pulai (Alstronia pneumatophora), Jelutung (Dyera lowii), Sungkai (Peronema canescens), Rotan (Calamus spp.), Sengon (Albizia falcataria), Saga (Adenantera sp.) dan beberapa jenis lainnya.

Menurut Suryadiputra et al. (2005) terdapat beberapa jenis fauna di lahan gambut sekitar Sungai Puning, Kabupaten Barito Selatan, diantaranya yang termasuk mamalia, avifauna dan herpetofauna. Jenis mamalia diantaranya adalah Malu-malu Kukang (Nycticebus coucang), Lutung, Cekong (Presbytis cristatus), Beruk (Macaca namestrina) (dilindungi UU dan termasuk appendix II CITES), serta Ungko (Hylobates agliss) dan Kelawat (Hylobates mulleri) (dilindungi UU, termasuk appendix I CITES, kriteria IUCN terancam punah dengan status EN (Endangered) atau Genting). Fauna lainnya seperti Rusa Sambar (Cervus unicolor) dan Kijang (Mantiacus muntjak) (dilindungi UU), Kucing kuwuk (Felis bengalensis) (dilindungi UU dan termasuk appendix I CITES) dan Beruang madu (Helarctos Malayanus) (dilindungi UU, termasuk appendix I 
CITES, kriteria IUCN terancam punah dengan status EN (Endangered) atau Genting).

Termasuk Avifauna diantaranya Bangau Tongtong (Leptoptilos javanicus) (dilindungi UU dan status IUCN VU (Vulnerable) atau rawan), Elang Bondol (Halisatur indus), Elang Laut Paruh Putih (Haliaeetus leucogaster), Elang ular Bido (Spilomis cheela), dan Alap-alap capung (Microhierax fringilarius) (dilindungi UU dan termasuk appendix II CITES), Raja udang meninting (Alcedo meninting), Pekaka emas (Palergopsis capensis) dan kelompok burung madu (Nectariniidae) (dilindungi UU), serta Kangkareng perut putih (Anthracoceros albirostris) (dilindungi UU dan termasuk appendix II CITES).

Herpetofauna diantaranya Buaya Senyulong (Tomistoma schlegelii) (dilindungi UU, termasuk appendix I CITES, status IUCN Endangerd Species (EN)), Beyuku dan Bajuku (Oritia borneensis) (dilindungi UU, termasuk appendix II CITES, status IUCN NT (near threatened) atau mendekati terancam punah), serta Labi-labi (Amida cartalaginea), Ular Sawah (Phyton reticulatus), Ular Kobra dan Tedung (Ophiophagus hannah) (appendix II CITES.)

Menurut Iqbal dan Setijono (2011) beberapa jenis burung di hutan rawa gambut Merang-Kepayang, Kabupaten Musi-Banyuasin, Sumatera Selatan ditemukan lebih dari 156 jenis burung. Terdapat 4 jenis burung terancam secara global, 25 mendekati terancam punah, 39 jenis dilindungi UU, dan 27 jenis termasuk dalam appendix CITES. Jenis seperti Burung Alap-alap capung suku falconidae (Microhierax fringillarius) (dilindungi UU dan termasuk appendix II CITES), Nuri Tanau (Psittacula cyanurus) dan burung paruh bengkok seperti Betet ekor panjang (Psittacula longicauda) (dilindungi UU, termasuk appendix II CITES, dan kategori NT (Near Treathened)), Burung Hantu Serak suku Tytonidae seperti Serak Jawa (Tyto alba) (termasuk Appendix II CITES). Jenis burung Rangkong suku Bucerotidae seperti Enggang Khilingan (Anorrhinus galeritus), Kangkareng Perut Putih (Anthracoceros albirostris), Kangkareng Hitam (Anthracoceros malayanus), Rangkong Badak (Buceros rhinoceros) (dilindungi UU dan termasuk appendix II), burung sikatan dari suku Muscicapidae seperti Sikatan-rimba dada kelabu (Rhinomyias umbratillis) (termasuk burung migran dan NT (Near Treathened)), serta masih banyak lagi seperti burung jalak, burung madu, dll.

Menurut Iqbal (2011) di kawasan hutan gambut Merang-Kepayang terdapat beberapa jenis ikan seperti Ikan Juara Panjang (Pangasius macronema) dan Ikan Betutu Suku Eleotrididae seperti Betutu (Oxyeleotris marmorata) (status LC (Least Concern) atau populasi di alam tidak diketahui), serta Ikan Betok dari suku Anabantidae seperti Betok (Anabas testudineus) atau Climbing Perch (status DD/Data Deficient atau kurang data). 
Berdasarkan data di atas, berbagai flora dan fauna telah hidup dan berkembang di ekosistem lahan basah, bahkan beberapa diantaranya termasuk dalam flora dan fauna yang dilindungi oleh hukum nasional dan internasional.

\subsection{Ketentuan internasional yang melindungi flora dan fauna pada ekosistem lahan gambut}

\subsubsection{Ketentuan hukum internasional yang bersifat hard law}

Ketentuan hukum internasional yang bersifat hard law yang dimaksudkan di sini adalah berbentuk perjanjian internasional dengan berbagai nama. Dalam praktek hukum lingkungan internasional ternyata suatu perjanjian internasional tidak hanya mengikat negara-negara saja atau organisasi internasional (Pramudianto 2017). Bahkan beberapa NGO juga memiliki keterikatan yang sama dengan subjek hukum internasional lainnya (Sands 1995). Menurut Suryokusumo (2003) dalam Pramudianto (2016) diperlukan tindakan hukum internasional yang juga memiliki moral dan etika untuk mencegah semakin parahnya tingkat kepunahan jenis fauna tertentu baik di tingkat regional maupun global. Oleh karena itu, terdapat beberapa ketentuan hukum internasional khususnya perjanjian internasional mengatur perlindungan ekosistem alam termasuk ekosistem lahan gambut beserta flora dan fauna terutama keanekaragaman hayatinya seperti UNCBD (United Nations Convention on Biological Diversity) tahun 1992. Konsep-konsep mengenai keanekaragaman hayati yang telah ada perlu direalisasikan dalam bentuk hukum internasional yang harus ditaati oleh negara-negara. Urgensi perlindungan terhadap keanekaragaman hayati karena keanekaragaman hayati merupakan kekayaan dunia yang bermanfaat bagi proses kehidupan di bumi yang juga kelak akan diwariskan pada generasi mendatang. Pemerintah Indonesia telah meratifikasi UNCBD melalui UU Nomor 5 Tahun 1994 (1 Agustus 1994). Konvensi ini menegaskan pentingnya peran ekosistem lahan gambut seperti yang direkomendasikan dalam Resolution VII/15 yang dihasilkan dari COP ke-7 UNCBD. Dalam Strategic Goals Aichi Target yang diadopsi pada Conferences of the Parties (COP) UNCBD ke-10, ekosistem menjadi sangat penting untuk dilindungi melalui pembentukan wilayah perlindungan. Tentu saja ekosistem lahan gambut juga menjadi bagian penting dalam target yang harus dilindungi termasuk flora dan faunanya.

Sementara itu ekosistem lahan gambut termasuk ekosistem lahan basah yang pengaturan internasionalnya melalui Ramsar Convention 1971 atau Ramsar Convention on Wetlands of International Importance, Especially as Waterfowl Habitat atau Konvensi Ramsar mengenai Lahan Basah Penting Internasional Khususnya sebagai Habitat Unggas Air yang ditandatangani di Teheran, Iran tahun 1971. Konvensi ini kemudian diamandemen di Paris (3 Desember 1982). Amandemen ini sering disebut juga Protokol Paris. Konvensi ini memiliki daftar 
yang dirancang untuk melindungi kawasan yang memenuhi kriteria penting secara internasional dan disusulkan oleh negara-negara peserta Konvensi Ramsar 1971 dan harus mendapat persetujuan melalui Konferensi Para Pihak (Conference of the Parties/COP). Pemerintah Indonesia telah meratifikasi konvensi ini, oleh karenanya di Indonesia terdapat Taman Nasional seperti Taman Nasional Barbak di Jambi yang telah masuk ke dalam Ramsar List. Berkaitan dengan ekosistem lahan gambut, konvensi ini telah berhasil menyepakati Recommendation 6.1: Conservation of Peatlands dan Guidelines for Global Action on Peatlands (GAP) yang menjadi acuan negara-negara pihak konvensi Ramsar.

CITES 1973 (Convention on International Trade in Endangered Species Wildlife Flora and Fauna) atau Konvensi Internasional Mengenai Perdagangan Spesies Satwa dan Tumbuhan Langka yang mengatur mengenai perdagangan internasional flora dan fauna yang terancam punah juga mengatur beberapa flora dan fauna yang terdapat pada ekosistem lahan gambut. CITES 1973 ditandatangani di Washington pada 3 Maret 1973, berlaku penuh pada 1 Juli 1975, serta terdiri atas 25 Pasal dan 4 Lampiran (Appendix). Lampiran I berisi ketentuan mengenai larangan sama sekali (total ban) perdagangan terhadap jenis spesies flora dan fauna yang tergolong sangat langka. Lampiran II berisi berbagai spesies yang langka namun masih diperbolehkan diperdagangkan dengan pengawasan ketat. Lampiran III diberlakukan pada jenis spesies yang menurut negaranya langka dan perlu izin khusus dari konvensi. Lampiran IV diperbolehkan izin perdagangan bagi spesies yang belum termasuk dalam appendix I-III dan dokumen-dokumen serta formulir yang harus dilengkapi persyaratannya. Hingga tahun 1992, sudah 117 negara menandatangani konvensi ini. Konvensi ini mengalami 2 kali amandemen yaitu Amandemen Protocol 1979 dan Amandemen Protocol 1983. Pemerintah Indonesia telah meratifikasi CITES 1973 melalui KepPres Nomor 43 Tahun 1978 (15 Desember 1978) dan Amandemen tahun 1979 melalui KepPres Nomor 1 Tahun 1987 (14 Januari 1987). Beberapa fauna yang dilindungi dalam ekosistem gambut diantaranya adalah Buaya Senyulong (Tomistoma schlegelii), Beruk (Macaca namestrina), Burung Hantu Serak Suku Tytonidae seperti Serak Jawa (Tyto alba), dll.

Ekosistem lahan gambut telah diakui memiliki peran dalam mengatasi dampak perubahan iklim. Berkaitan dengan komitmen untuk menurunkan emisi gas rumah kaca, terdapat Konvensi PBB mengenai Perubahan Iklim (United Nations Framework Convention on Climate Change) yang ditandatangani pada tahun 1992. Komitmen ini juga memperhatikan ekosistem lahan gambut sebagai penyerap gas-gas rumah kaca. Untuk menegaskan komitmen akan upaya menstabilkan dan menurunkan emisi gas rumah kaca maka Protokol Kyoto 
tahun 1997 menjadi dasar untuk melaksanakan UNFCCC dalam bentuk nyata. Saat ini masih berlangsung Periode Komitmen II Protokol Kyoto 1997 hingga 2020. Sementara itu Paris Agreement yang disepakati di Paris (2015), diharapkan melalui kesepakatan NDC akan dimulai pada 2020 hingga 2030. Walaupun tidak diatur secara khusus, namun beberapa keputusan dalam COP UNFCCC telah mengamanatkan peran penting dari berbagai ekosistem termasuk ekosistem lahan gambut sebagai penyerap gas-gas rumah kaca. Dengan demikian maka ekosistem lahan gambut sebagai penyerap gas-gas rumah kaca (GRK) khususnya $\mathrm{CO}_{2}$, akan semakin berperan penting di masa mendatang.

Selain konvensi global, terdapat beberapa konvensi internasional regional seperti di Eropa yakni Bonn Convention on Conservation of Migratory Species of Wild Animals atau Konvensi Eropa Mengenai Perlindungan Satwa Liar yang Tergolong Spesies Berpindah atau Bonn Convention ditandatangani tahun 1979. Konvensi ini mengatur mengenai satwa yang berpindah antar negara. Terdapat juga Bern Convetion on the Conservation of Eroupea Wildlife and Their Natural Habitats atau Konvensi mengenai Pelestarian Satwa Liar Eropa dan Habitat Alamnya yang ditandatangani tahun 1979. Konvensi ini berupaya melestarikan satwa dan habitat alamnya dari ancaman kepunahan. Dalam salah satu pasalnya, Pasal 40 menyatakan:

"appropriate and necessary measures [shall be taken to ensure the conservation of the habitats of the vvlld flora and fauna species, especially those Wed in the Appendices I and II, and the conservation of endangered natural habitats".

Di Asia Tenggara terdapat ASEAN Agreement on the Nature and Natural Conservation atau Persetujuan ASEAN mengenai Konservasi Alam dan Sumber Daya Alam yang ditandatangani di Kuala Lumpur pada 9 Juli 1985. Tujuan dari persetujuan ini adalah mendukung kerja sama dan tindakan-tindakan individu negara untuk pelestarian dan pengelolaan sumber daya alam di wilayah ASEAN. Persetujuan ini mengatur mengenai perlindungan flora dan fauna serta habitatnya. Hingga saat ini persetujuan ini mengalami penundaan karena ada negara ASEAN yang tidak meratifikasi. Saat ini juga dikembangkan ASEAN Biodiversity berdasarkan Agreement untuk mengembangkan keanekaragaman Hayati di ASEAN termasuk di ekosistem lahan gambut.

Negara-negara Afrika juga telah sepakat menandatangani African Convention atau Konvensi Afrika mengenai Perlindungan Alam dan Sumber Daya Alam. Konvensi ini bertujuan untuk mengambil tindakan baik individu maupun tindakan bersama untuk konservasi, penggunaan, pengembangan sumbersumber tanah dan air, serta pelestarian satwa dan tumbuhan demi kesejahteraan generasi sekarang maupun mendatang. Konvensi ini terdiri atas Pembukaan, 25 Pasal, dan Daftar Spesies yang dilindungi dengan pembagian kelas A dan B. Ditandatangani di Aljir, Aljazair (15 September 1968). Konvensi 
Afrika berupaya untuk melindungi sumber daya alam termasuk flora dan fauna serta habitatnya.

\subsubsection{Ketentuan hukum internasional yang bersifat soft law}

Beberapa ketentuan hukum internasional yang tidak mengikat hukum secara penuh (non legally binding) atau disebut soft law, bagi negara-negara pihak terkait dengan ekosistem lahan gambut masih sangat sedikit. Beberapa produk soft law ini masih berfokus pada perlindungan ekosistem lahan gambut dan sangat jarang menyinggung flora dan fauna yang ada, seperti Riau Declaration on Peatlands and Climate Change 2006 yang merupakan hasil dari The Workshop on Vulnerability of Carbon Pools in Tropical Peatlands di Pekanbaru, Riau, Sumatera (23-26 Januari 2006) yang ditandatangani 12 negara. Dalam deklarasi ini salah satunya menegaskan bahwa:

"... promote rehabilitation and sustainable use of peatlands in South East Asia to provide multiple benefits to the people in the region and safeguard the global environment."

Sementara itu Recommendation 6.1 : Conservation of Peatlands yang merupakan salah satu hasil dari 6th Meeting of the Conference of the Contracting Parties Ramsar Convention 1971 yang diselenggarakan di Brisbane, Australia (19-27 Maret 1996) menegaskan bahwa:

"... peat-dominated wetland systems, known as "peatlands", including bogs, fens, carrs, mires, "bofedales", peatswamp forest, and other similar terms, are important wetland types hitherto under-represented in the work of the Convention."

Hanya Guidelines for Global Action on Peatlands (GAP) yang merupakan hasil dari 8th Meeting of the Conference of the Contracting Parties to the Convention on Wetlands (Ramsar, Iran, 1971) yang diselenggarakan di Valencia, Spain, pada 1826 November 2002, yang menyinggung keberadaan flora dan fauna. Pada bagian 7 Guidelines ini menyatakan:

"7. Peatlands play a special role in conserving global biodiversity because they are the refugia of some of the rarest and most unusual species of wetland-dependent flora and fauna".

\subsubsection{Dokumen internasional lainnya}

Dokumen terpenting terkait dengan perlindungan flora dan fauna terutama status keberadaan dan perlindungannya diatur dalam IUCN Red Data List yang merupakan buku yang berisi informasi dan daftar kategori status konservasi yang diterbitkan oleh IUCN (International Union for the Conservation of Nature). Kategori konservasi mengalami berbagai perubahan mulai dari Versi 1.0: Mace and Lande (1991) yang merupakan dokumen pertama yang mendiskusikan aturan baru untuk klasifikasi. Selanjutnya Versi 2.0: Mace et al. (1992) yang merupakan revisi besar terhadap versi 1.0. Selanjutnya Versi 2.1: 
IUCN (1993), Versi 2.2: Mace and Stuart (1994), Versi 2.3: IUCN (1994), Versi 3.0: IUCN/SSC Criteria Review Working Group (1999), dan Versi 3.1: IUCN (2001). Saat ini yang digunakan berdasarkan IUCN Red List versi 3.1 meliputi Extinct (EX; Punah); Extinct in the Wild (EW; Punah Di Alam Liar); Critically Endangered (CR; Kritis), Endangered (EN; Genting atau Terancam), Vulnerable (VU; Rentan/Rawan), Near Threatened (NT; Hampir Terancam), Least Concern (LC; Berisiko Rendah), Data Deficient (DD; Informasi Kurang), dan Not Evaluated (NE; Belum Dievaluasi). Pertama kali dikeluarkan pada tahun 1984 dan IUCN Red Data Book biasanya selalu dievaluasi statusnya setiap lima tahun sekali atau setidaknya sepuluh tahun sekali.

Dari semua perjanjian internasional di atas, ternyata tidak banyak yang menyinggung flora dan fauna pada ekosistem lahan gambut. Flora dan fauna yang diatur, masih bersifat umum dan diperlukan tindakan yang lebih lanjut. Sebagai contoh upaya ini dilakukan oleh Konvensi Ramsar 1971 yang umumnya mengatur perlindungan unggas pada lahan basah. Namun tindak lanjut dari konvensi ini adalah berupaya melindungi flora dan fauna pada lahan gambut seperti tercantum dalam Guidelines for Global Action on Peatlands (GAP) yang merupakan salah satu produk kesepakatan yang dihasilkan dalam COP Ramsar 1971.

Diluar perjanjian internasional seperti dokumen internasional lainnya, juga berupaya melindungi flora dan fauna pada lahan gambut yang diantaranya status data keberadaan flora dan fauna yang berada dalam ekosistem lahan gambut. Data ini menjadi penting sebagai status dan kondisi keberadaan flora dan fauna di alam terutama pada ekosistem lahan gambut terutama bagaimana upaya perlindungannya jika status flora dan fauna tersebut semakin punah. Agar tidak semakin punah, maka diperlukan batasan-batasan, misalnya dapat berupa pengurangan, pembatasan, bahkan pelarangan melalui perdagangan dan penangkapan atas flora dan fauna di pasar nasional maupun internasional.

Oleh karena itu, diperlukan upaya dan komitmen yang lebih kuat lagi terutama dalam mengimplementasikan dan mengoperasionalkan perjanjian internasional di atas khususnya dalam kerangka melindungi flora dan fauna yang ada di ekosistem lahan gambut di berbagai negara.

\subsection{Peraturan nasional yang melindungi flora dan fauna pada ekosistem lahan gambut}

\subsubsection{Peraturan nasional}

Beberapa peraturan nasional terkait dengan upaya perlindungan ekosistem secara umum diatur diantaranya melalui UU Nomor 32 Tahun 2009 tentang Perlindungan dan Pengelolaan Lingkungan Hidup dan UU Nomor 41 Tahun 1999 tentang Kehutanan yang memiliki beberapa peraturan pelaksanaannya diantaranya PP Nomor 71 Tahun 2014 tentang Perlindungan 
dan Pengelolaan Ekosistem Gambut dan PP Nomor 57 Tahun 2016 tentang Perubahan Atas PP Nomor 71 Tahun 2014 tentang Perlindungan dan Pengelolaan Ekosistem Gambut. Peraturan nasional terkait dengan flora dan fauna diatur dalam UU Nomor 5 Tahun 1990 tentang Konservasi Sumber daya Alam Hayati dan Ekosistemnya dan UU Nomor 5 Tahun 1994 tentang Ratifikasi Konvensi PBB tentang Keanekaragaman Hayati (UNCBD). Peraturan pelaksanaannya diatur PP Nomor 7 Tahun 1999 tentang Pengawetan Jenis Tumbuhan dan Satwa dan PP Nomor 8 Tahun 1999 tentang Pemanfaatan Jenis Tumbuhan dan Satwa Liar.

Dalam UU maupun PP tersebut diatur bagaimana melestarikan flora dan fauna serta tindakan yang mendukung ekosistemnya. Namun, UU dan PP ini tidak secara jelas dan khusus mengatur mengenai flora dan fauna pada lahan gambut. Hanya saja diberikan rambu-rambu secara prinsip dalam Pasal 21 ayat 1 UU Nomor 5 Tahun 1990 berupa larangan seperti :

a. Mengambil, menebang, memiliki, merusak, memusnahkan,memelihara, mengangkut, dan memperniagakan tumbuhan yang dilindungi atau bagian-bagiannya dalam keadaan hidup atau mati;

b. Mengeluarkan tumbuhan yang dilindungi atau bagian-bagiannya dalam keadaan hidup atau mati dari suatu tempat di Indonesia ke tempat lain di dalam atau di luar Indonesia.

Sedangkan Pasal 21 ayat 2 menegaskan larangan :

a. Menangkap, melukai, membunuh, menyimpan, memiliki, memelihara, mengangkut, dan memperniagakan satwa yang dilindungi dalam keadaan hidup;

b. Menyimpan, memiliki, memelihara, mengangkut, dan memperniagakan satwa yang dilindungi dalam keadaan mati;

c. Mengeluarkan satwa yang dilindungi dari suatu tempat di Indonesia ke tempat lain di dalam atau di luar Indonesia;

d. Memperniagakan, menyimpan atau memiliki kulit, tubuh atau bagianbagian lain satwa yang dilindungi atau barang-barang yang dibuat dari bagian-bagian satwa tersebut atau mengeluarkannya dari suatu tempat di Indonesia ke tempat lain di dalam atau di luar Indonesia;

e. Mengambil, merusak, memusnahkan, memperniagakan, menyimpan atau memiliki telur dan/atau sarang satwa yang dilindungi.

Tentu saja larangan di atas juga berlaku pada flora dan fauna yang berada di ekosistem lahan gambut. Hal ini agar perlindungan flora dan fauna juga terjamin pada ekosistem lahan gambut di Indonesia.

\subsubsection{Peraturan sektor}

Peraturan di tingkat sektor yang mengatur mengenai lahan gambut diantaranya Peraturan Menteri Kehutanan Nomor P.55/Menhut-II/2008, 
Peraturan Menteri Lingkungan Hidup dan Kehutanan Nomor P.14/MENLHK/ SEKJEN/KUM.1/2/2017, Peraturan Menteri Lingkungan Hidup dan Kehutanan Nomor P.15/MENLHK/ SEKJEN/KUM.1/2/2017, Peraturan Menteri Lingkungan Hidup dan Kehutanan Nomor P.16/MENLHK/SEKJEN/KUM.1/2/2017, serta beberapa peraturan sektor lainnya. Terkait flora dan fauna ada beberapa peraturan di atas yang berupaya untuk melindungi flora dan fauna. Sebagai contoh dalam Peraturan Menteri Lingkungan Hidup dan Kehutanan Nomor P.14/MENLHK/SEKJEN/ KUM.1/2/2017 tentang Tata Cara Inventarisasi dan Penetapan Fungsi Ekosistem Gambut khususnya pasal 14 juga menginventarisasi keberadaan flora dan fauna yang dilindungi dan Pasal 16 mengenai spesies yang dilindungi sesuai dengan peraturan perundangundangan. Pada Peraturan Menteri Lingkungan Hidup dan Kehutanan Nomor P.15/MENLHK/SEKJEN/KUM.1/2/2017 tentang Tata Cara Pengukuran Muka Air Tanah Di Titik Penaatan Ekosistem Gambut khususnya pada Pasal 8 dinyatakan bahwa pada saat pengukuran di titik penaatan juga harus memperhatikan keberadaan flora dan fauna yang dilindungi. Pada Peraturan Menteri Lingkungan Hidup dan Kehutanan Nomor P.16/MENLHK/ SEKJEN/KUM.1/2/2017 tentang Pedoman Teknis Pemulihan Fungsi Ekosistem Gambut pada pasal 14 ayat 2 menegaskan bahwa kegiatan rehabilitasi dilakukan dengan mengutamakan jenis tanaman asli. Sedangkan pada Pasal 14 ayat 3 menyatakan jenis tanaman ini diatur dalam lampiran peraturan ini. Dalam lampiran tersebut terdapat jenis flora seperti Jelutung Jawa (Dyerapolyphylla), Pulai Rawa (Alstonia pneumatophora), Terentang (Campnosperma coriaceum), Ramin (Gonystylus bancanus), Meranti Rawa (Shorea pauciflora, Shorea tesmanniana, Shorea uliginosa), Kapur Naga (Calophyllum macrocarpum), Rotan (Calamus spp.), Sagu (Metroxylon spp.) dan masih banyak lagi.

Dengan demikian keberadaan beberapa peraturan sektor diatas juga memberikan gambaran mengenai kewajiban untuk melindungi flora dan fauna yang berada di ekosistem lahan gambut. Hal ini menjadi penting, karena perhatian terhadap flora dan fauna yang dilindungi akan memberikan dampak positif seperti peningkatan kualitas ekosistem lahan gambut, terutama dari aspek keanekaragaman hayati.

\subsubsection{Peraturan daerah}

Hanya sedikit peraturan daerah yang mengatur ekosistem lahan gambut, itu pun sangat umum dan biasanya dikaitkan dengan kebakaran hutan ataupun tata ruang. Tidak banyak yang secara jelas dan tegas mengatur ekosistem lahan gambut secara khusus. Peraturan daerah yang secara tegas dan khusus terhadap gambut adalah PerDa Kabupaten Humbang Hasundutan Nomor 8 Tahun 2013 tentang Lahan Gambut. Dalam penjelasan Perda ini disebutkan bahwa dalam 
kondisi alamiahnya lahan gambut memiliki pH rendah (asam) dan miskin unsur hara, dengan demikian lahan gambut menjadi habitat yang unik bagi keanekaragaman hayati tertentu yang memiliki kemampuan untuk hidup pada kondisi tersebut. Peraturan daerah ini secara tidak langsung mengakui keberadaan flora dan fauna yang unik yang memiliki kemampuan untuk hidup dalam ekosistem lahan gambut.

Mengingat sangat sedikitnya peraturan daerah yang peduli pada ekosistem lahan gambut mengakibatkan kurangnya perlindungan pada flora dan fauna yang hidup dalam ekosistem tersebut. Dengan kondisi ini maka perlindungan pada flora dan fauna di ekosistem lahan gambut sangat kurang dan dapat berakibat terhadap semakin terancam punahnya jenis flora dan fauna. Diperlukan upaya untuk meningkatkan perlindungan flora dan fauna pada ekosistem lahan gambut melalui peraturan yang lebih operasional seperti peraturan gubernur, bupati ataupun walikota. Tidak cukup peraturan daerah saja, karena peraturan daerah masih bersifat umum dan biasanya belum rinci untuk dioperasionalkan.

\section{KESIMPULAN DAN SARAN}

Dalam kebijakan internasional, ekosistem lahan gambut memiliki peran penting dan menjadi salah satu ekosistem yang harus dilindungi di masa mendatang. Di dalam ekosistem ini hidup berbagai jenis flora dan fauna terutama yang dilindungi oleh hukum nasional dan hukum internasional. Selain dilindungi oleh hukum, juga dilindungi melalui organisasi internasional seperti International Union for Conservation Nature (IUCN) yang memiliki IUCN Red Data List yang banyak dijadikan acuan di hampir seluruh negara. Berbagai perangkat tersebut telah memberikan manfaat diantaranya menegaskan akan pentingnya perlindungan flora dan fauna beserta ekosistemnya termasuk statusnya apakah termasuk punah, terancam punah, langka atau bahkan tidak tersedia data.

Sementara itu kebijakan nasional Indonesia terhadap ekosistem lahan gambut mulai menjadi perhatian dengan terbentuknya Badan Restorasi Gambut (BRG). Dengan adanya BRG yang kedudukannya berada di bawah Presiden, diharapkan terjadi perubahan penting dalam memahami dan menangani ekosistem lahan gambut termasuk flora dan faunanya. Tidak saja di tingkat nasional, tetapi juga di daerah yang terdapat ekosistem ini, diharapkan dapat mengambil kebijakan daerah untuk meningkatkan luasan ekosistem lahan gambut sebagai habitat berbagai flora dan fauna. Walaupun saat ini, masih sangat sedikit aturan di daerah yang khusus mengatur mengenai ekosistem lahan gambut, terutama perlindungan flora dan fauna di ekosistem lahan gambut. 
Ekosistem lahan gambut ternyata juga berperan dalam mengatasi perubahan iklim. Melalui Paris Agreement 2015 dengan NDC sebagai komitmen yang akan dilaksanakan tahun 2020, maka diperlukan kesiapan ekosistem lahan gambut sebagai unsur yang dapat mengurangi dampak dari perubahan iklim. Karena itu ekosistem ini akan menjadi penting di masa mendatang baik dalam kerangka perlindungan flora dan fauna maupun dalam mengatasi dampak perubahan iklim.

\section{DAFTAR PUSTAKA}

Iqbal M. 2011. Ikan-ikan di hutan rawa gambut Merang-Kepayang dan sekitarnya. Merang REDD Pilot Project (MRPP)-Deutsche Gesellschaft fur Internationale Zusammenarbeit (GIZ). Palembang.

Iqbal M dan Setijono D. 2011. Burung-burung di hutan rawa gambut MerangKepayang dan sekitarnya. Merang REDD Pilot Project (MRPP)-Deutsche Gesellschaft fur Internationale Zusammenarbeit (GIZ). Palembang.

KepPres (Keputusan Presiden) Nomor 43 Tahun 1978 tentang pengesahan Convention On International Trade In Endangered Species of Wild Fauna and Flora.

KepPres (Keputusan Presiden) Nomor 1 Tahun 1987 tentang pengesahan Amandemen 1979 atas Convention On International Trade In Endangered Species Of Wild Fauna And Flora, 1973.

Mudiyarso D, Rosalina U, Hairiah K, Muslihat L, Suryadiputra INN dan Adijaya. 2004. Petunjuk lapangan: pendugaan cadangan karbon pada lahan gambut. Wetlands International-IP. Bogor.

Najiyati S, Asmana A dan Suryadiputra INN. 2005a. Pemberdayaan masyarakat di lahan gambut. Proyek climate change, forests and peatlands in Indonesia. Wetlands International-Indonesia Programme and Wildlife Habitat Canada. Bogor.

Najiyati S, Muslihat L dan Suryadiputra INN. 2005b. Panduan pengelolaan lahan gambut untuk pertanian berkelanjutan. Proyek climate change, forests and peatlands in Indonesia. Wetlands International-Indonesia Programme and Wildlife Habitat Canada. Bogor.

PerDa (Peraturan Daerah) Kabupaten Humbang Hasundutan Nomor 8 Tahun 2013 tentang lahan gambut.

PerMenHut (Peraturan Menteri Kehutanan) Nomor P.55/Menhut-II/2008 tentang rencana induk rehabilitasi dan konservasi kawasan pengembangan lahan gambut di Kalimantan Tengah.

PerMenLHK (Peraturan Menteri Lingkungan Hidup dan Kehutanan) Nomor P.14/MENLHK/SEKJEN/KUM.1/2/2017 tentang tata cara inventarisasi dan penetapan fungsi ekosistem gambut. 
PerMenLHK (Peraturan Menteri Lingkungan Hidup dan Kehutanan) Nomor P.15/MENLHK/ SEKJEN/KUM.1/2/2017 tentang tata cara pengukuran muka air tanah di titik penaatan ekosistem gambut.

PerMenLHK (Peraturan Menteri Lingkungan Hidup dan Kehutanan) Nomor P.16/MENLHK/SEKJEN/KUM.1/2/2017 tentang pedoman teknis pemulihan fungsi ekosistem gambut.

PerMenPU (Peraturan Menteri Pekerjaan Umum) Nomor 64/PRT/1993 tentang reklamasi rawa.

PP (Peraturan Pemerintah) Nomor 27 Tahun 1991 tentang rawa.

PP (Peraturan Pemerintah) Nomor 7 Tahun 1999 tentang pengawetan jenis tumbuhan dan satwa.

PP (Peraturan Pemerintah) Nomor 8 Tahun 1999 tentang pemanfaatan jenis tumbuhan dan satwa liar.

PP (Peraturan Pemerintah) Nomor 71 Tahun 2014 tentang perlindungan dan pengelolaan ekosistem gambut.

PP (Peraturan Pemerintah) Nomor 57 Tahun 2016 tentang perubahan atas PP Nomor 71 Tahun 2014 tentang perlindungan dan pengelolaan ekosistem gambut.

Pramudianto A. 2016. Ketentuan etika dalam perjanjian internasional di bidang perlindungan fauna. Jurnal Lingkungan dan Pembangunan 2(2):438-452.

Pramudianto A. 2017. Hukum lingkungan internasional. CV Rajawali. Jakarta.

Sands P. 1995. Principle of international environmental law: framework, standards and implementation, Vol I. Manchester University Press. Manchester.

Suryadiputra INN, Dohong A, Waspodo RSB, Muslihat L, Lubbis IR, Hasudungan F dan Wibisono ITC. 2005. Panduan penyekatan parit dan saluran di lahan gambut bersama masyarakat. Proyek climate change, forests and peatlands in Indonesia. Wetlands International-Indonesia Programme and Wildlife Habitat Canada. Bogor.

UU (Undang-Undang) Nomor 5 Tahun 1990 tentang konservasi sumber daya alam hayati dan ekosistemnya.

UU (Undang-Undang) Nomor 5 Tahun 1994 tentang pengesahan United Nations Convention on Biological Diversity (Konvensi Perserikatan Bangsa-Bangsa Mengenai Keanekaragaman Hayati).

UU (Undang-Undang) Nomor 41 Tahun 1999 tentang kehutanan.

UU (Undang-Undang) Nomor 32 Tahun 2009 tentang perlindungan dan pengelolaan lingkungan hidup. 